\title{
RESEARCH
}

\section{Tyrosine kinase inhibitor therapy and metabolic remodelling in papillary thyroid cancer}

\author{
Michael Wagner1,*, Melinda Wuest1,*, Ana Lopez-Campistrous², Darryl Glubrecht1', Jennifer Dufour', \\ Hans-Soenke Jans ${ }^{1}$, Frank Wuest ${ }^{1}$ and Todd P W McMullen ${ }^{1,2}$ \\ Department of Oncology, Cross Cancer Institute, University of Alberta, Edmonton, Canada \\ 2Department of Surgery and Surgical Oncology, 2D, Walter C Mackenzie Health Sciences Centre, University of Alberta, Edmonton, Canada
}

Correspondence should be addressed to F Wuest or T P W McMullen: wuest@ualberta.ca or todd.mcmullen@ualberta.ca

*(M Wagner and M Wuest contributed equally to this work)

\begin{abstract}
Targeted therapy is increasingly used to manage metastatic papillary thyroid cancer. The focus of the present study was to examine glucose metabolism and tumor responses for thyroid cancer xenografts expressing the glycolytic pathway modulators platelet-derived growth factor receptor (PDGFR) and BRAFV600E. Radiolabelled glucose derivative [ $\left.{ }^{18} \mathrm{~F}\right]$ FDG was used to analyze the effects of PDGFR blockade with imatinib, BRAF blockade with vemurafenib, as well as combined PDGFR and BRAF blockade in vitro and in vivo with PET. Dynamic PET data was correlated with immunohistochemistry staining and kinetic analysis for facilitative glucose transporter 1 (GLUT1) and hexokinase-II (HK2). Vemurafenib decreased [18F]FDG uptake in BCPAP cells in vitro; however, it was increased by $70 \%$ with imatinib application to BCPAP cells. This metabolic response to tyrosine kinase inhibition required BRAFV600E as it was not seen in cell lines lacking mutated BRAF (TPC1). In xenografts, imatinib therapy in BCPAP thyroid tumour-bearing mice significantly increased $\left[{ }^{18} \mathrm{~F}\right] \mathrm{FDG}$ uptake and retention (>30\%) in BCPAP tumours with PDGFR $\beta$ or both $(\alpha+\beta)$ isoforms. Kinetic analysis revealed that the increased glucose uptake is a consequence of increased phosphorylation and intracellular trapping of [ $\left.{ }^{18} \mathrm{~F}\right] \mathrm{FDG}$ confirmed by an increase in HK2 protein expression and activity, but not GLUT1 activity. BRAF inhibition alone, or combined PDGFR and BRAF inhibition, reduced ( 60\%) $\left[{ }^{18} \mathrm{~F}\right]$ FDG uptake in both types of BCPAP $(\beta$ or $\alpha+\beta)$ tumours. In terms of tumour growth, combination therapy with imatinib and vemurafenib led to a near abolition of the tumors ( $90 \%$ reduction), but single therapy for BCPAP with PDGFR $\alpha$ expression was much less effective. In summary, imatinib led to a paradoxical increase of [ $\left.{ }^{18} \mathrm{~F}\right] \mathrm{FDG}$ uptake in xenografts that was reversed through BRAFV600E inhibition. The present data show that metabolic reprogramming in thyroid cancer occurs as a consequence of BRAF-mediated upregulation of HK2 expression that may permit tumour growth with isolated blockade of upstream tyrosine kinase receptors.
\end{abstract}
Key Words
- thyroid cancer
- $\left[{ }^{18} \mathrm{~F}\right] \mathrm{FDG}$ PET
- Imatinib
- Vemurafenib
- BRAF mutation
- PDGFR

Endocrine-Related Cancer (2020) 27, 495-507
C) 2020 Society for Endocrinology Published by Bioscientifica Ltd. Printed in Great Britain 


\section{Introduction}

Papillary thyroid cancer (PTC) is the most common type of thyroid cancer. PTC, in the majority of cases, will respond to a combination of surgery and radioactive iodine for treatment of metastatic disease. However, approximately $15 \%$ of thyroid cancer patients are predisposed to a poor prognosis due to locally advanced or diffuse metastatic disease (Matrone et al. 2017). For these patients, there has been a significant attempt to identify suitable targeted therapies. More than 15 studies have examined different tyrosine kinase inhibitors in an effort to determine effective drug regimens for patients with iodine-refractory disease (Durante et al. 2006, Matrone et al. 2017, Valerio et al. 2017). Since most of these drugs target multiple receptor classes including vascular endothelial growth factor receptor (VEGFR), c-KIT, re-arranged during transfection receptor (RET), and platelet-derived growth factor receptor $(\mathrm{PDGFR} \alpha / \beta)$, the clinical trial results demonstrate mixed efficacy and are difficult to compare between the different tyrosine kinase inhibitors. Targeted inhibition of tyrosine kinase receptors such as PDGFR or VEGFR can induce compensatory responses in pERK and other pathways that may abrogate the effects of TKI treatment (EkpeAdewuyi et al. 2016, Lopez-Campistrous et al. 2016). The latter study found that pharmacological and antibodymediated blockade of PDGFR $\alpha$ led to an upregulation of pERK expression in BCPAP cells. Moreover, many of those drugs have exhibited considerable side-effect profiles that lead to substantial patient drop-out rates and limited use for patients with metastatic, but slowly progressing, disease (Klein Hesselink et al. 2015, Viola et al. 2016, Liu et al. 2018).

Patient selection and the application of tyrosine kinase inhibitors for thyroid cancer, such as imatinib, lenvatinib, or sorafenib, remain empiric in nature. However, preclinical and clinical research is still ongoing using other TKIs to determine their specific efficacy and how the multi-targeting compounds result in a specific overall effect on thyroid cancer cells in vivo. The ability to assess TKI therapy efficacy remains limited. Non-invasive molecular imaging techniques such as PET using $\left[{ }^{18} \mathrm{~F}\right] \mathrm{FDG}$ have been often applied to analyse effects of tyrosine kinase inhibitors in vivo. For solid tumours, [18F]FDG-PET represents the 'gold standard' radiotracer for oncologic imaging and it is used extensively for monitoring response to therapy (Farwell et al. 2014, Sheikhbahaei et al. 2017). Tyrosine kinase inhibitors are known to suppress growthfactor-driven glycolysis in cancer (Poliaková et al. 2018), implying that the glucose derivative [18${ }^{18}$ F]FDG-PET can be used to quantify its biological response in vivo. The success of receptor kinase blockade has been monitored at an early stage with [18F]FDG-PET imaging in many forms of cancer including lung (Ma et al. 2017), melanoma (Wong et al. 2017), gastrointestinal stromal tumours (Van den Abbeele et al. 2012) and renal cell carcinoma (Vercellino et al. 2009, Ueno et al. 2012). While many studies have examined the role of PET imaging for diagnosing thyroid cancer, few studies have examined its use in monitoring therapy outside of small numbers in clinical trials (Marcus et al. 2014, Haugen et al. 2016, Takeuchi et al. 2018). It is known that increased $\left.{ }^{18} \mathrm{~F}\right] \mathrm{FDG}$ uptake into primary thyroid tumours and metastases correlates with dedifferentiation, the presence of the BRAF mutation, and poor prognosis (Nagarajah et al. 2015, Yang et al. 2017, Santhanam et al. 2018). However, [18F]FDG uptake into thyroid tumour lesions is highly variable and does not always correlate with severity of disease. Benign neoplasms may also often demonstrate an impressive glycolytic metabolic activity (Barrio et al. 2016). Thus, [18F]FDG-PET scans in thyroid cancer have been used selectively given the lack of understanding of glucose metabolism in this patient population.

Platelet-derived growth factor receptor is a tyrosine kinase receptor with two isoforms alpha $(\alpha)$ and beta $(\beta)$. Upon binding of PDGF ligands (AA-, BB- CC-, DD-), the receptors dimerize $(\alpha \alpha, \alpha \beta, \beta \beta)$ to activate downstream signalling pathways. PDGFR $\beta$ can be expressed in benign and malignant thyroid neoplasm but the PDGFR $\alpha$, and its associated cytokine ligand PDGF-AA, is linked to metastatic disease in thyroid cancer and may act as control regulator for cell dedifferentiation and resistance to radioactive iodine (Ekpe-Adewuyi et al. 2016, LopezCampistrous et al. 2016). PDGFR $\alpha$ activates the Akt, ERK, and STAT3 pathways in thyroid cancer and may also control glycolytic activity as demonstrated for other types of cancer including gastrointestinal stromal tumors (GIST) (Ran et al. 2013). The focus of the present study was to explore the potential functional link between oncogenic kinase drivers PDGFR $\alpha / \beta$ and the protooncogene BRAFV600E, and glucose metabolism in thyroid cancer. We also examined the influence of tyrosine kinase inhibitor therapy in a thyroid xenograft model with BCPAP (BRAFV600E mutation) that has native (PDGFR $\beta$ only) or engineered (PDGFR $\beta+\alpha)$ proteins expressed. In addition, the human papillary thyroid carcinoma cell line (TPC1) was used as a positive control expressing both PDGFR $\beta+\alpha$ and WT BRAF lacking V600E mutation. The goal was to analyse the role of PDGFR and BRAF signalling in glucose uptake and metabolism when cells 
are subjected to growth factor receptor inhibition, with and without blockade of BRAFV600E and in comparison to BRAF blockade alone. [18F]FDG-PET was used as a noninvasive tool to examine tumour glucose metabolism and the functional analysis of effects of PDGFR blockade alone with imatinib, with vemurafenib or in combination with BRAF inhibitor, vemurafenib.

\section{Materials and methods}

\section{General}

All chemicals and reagents were obtained from MilliporeSigma unless otherwise stated. Imatinib mesylate (amorphous form) and vemurafenib were obtained from Astatech Inc. (Bristol, PA, USA). Supersaturated solutions of imatinib mesylate in saline were freshly prepared for each animal experiments. Human recombinant PDGF-AA was obtained from Gibco (ThermoFisher Scientific). Doxycycline was purchased from Sigma-Aldrich Inc. Doxycycline $(0.5 \mathrm{mg} / 21$ days) slow-releasing pellets for animal experiments were from Innovative Research of America (Sarasota, FL, USA). Radiotracer [ $\left.{ }^{18} \mathrm{~F}\right]$ FDG was prepared at the Edmonton PET Center of the Cross Cancer Institute using a GE TracerLab MX automated synthesis unit (GE Healthcare Canada Inc.) according to established synthesis procedures (Hamacher et al. 1986).

\section{Cell culture}

PDGFR $\beta$ native and PDGFR $\alpha+\beta$ BCPAP cell lines were generated as previously described (Lopez-Campistrous et al. 2016). Briefly, BCPAP cells which had been obtained from the German Collection of Microorganisms and Cell Cultures $\mathrm{GmbH}$ (Deutsche Sammlung von Mikroorganismen und Zellkulturen GmbH, DSMZ; Braunschweig, Germany) were subjected to lentiviral transduction with doxycycline-inducible retrovirus system (Lenti-X Lentiviral Expression Systems; Clontech Laboratories Inc.) to express PDGFR $\alpha$ or mock protein. For WT BRAF control, TPC1 cells were used (LopezCampistrous et al. 2016). The cells were cultured as previously described (Wagner et al. 2018) using high glucose medium (DMEM with HEPES and L-glutamine) supplemented with $5 \mathrm{vol} \%$ foetal bovine serum (FBS) in presence of 100 units $/ \mathrm{mL}$ of penicillin and $100 \mu \mathrm{g} / \mathrm{mL}$ of streptomycin. To induce protein synthesis, doxycycline $(2 \mu \mathrm{g} / \mathrm{mL})$ was added at least $48 \mathrm{~h}$ before each in vitro experiment.

\section{Cellular uptake studies}

PDGF $\beta$ or $\alpha+\beta$ BCPAP $(75,000$ cells) with BRAFV600E mutation, or TPC1 $(60,000$ cells) as BRAF WT control, were seeded $48 \mathrm{~h}$ before the experiment with medium containing PDGF-AA (50 ng/mL) and doxycycline (2 $\mu \mathrm{g} / \mathrm{mL})$. $0.3 \mu \mathrm{M}$ imatinib was added if indicated. [18F]FDG uptake experiments were conducted in glucose free Krebs buffer with $1 \mathrm{~h}$ preincubation. Cells were incubated for the indicated time points, washed three times with PBS and lysed with RIPA buffer. Radioactivity was measured on a PerkinElmer Wizard 22480 Automatic Gamma Counter (Perkin Elmer). The radioactivity was normalized to the protein content in the cell lysate by using the Pierce BCA Protein Assay Kit (Pierce/ThermoFisher Scientific). Each experiment was done in triplicate using three wells each.

\section{Animals}

All animal experiments were conducted under the necessary ethical approval of the animal care committee of the Cross Cancer Institute. Male NSG mice were obtained from a breeding colony from Dr Lynne Postovit (Department of Oncology, University of Alberta, Edmonton, Canada). Around 3-month-old NSG mice were injected with $2.5 \times 10^{6}$ PDGFR $\beta$ expressing BCPAP cells in $100 \mu \mathrm{L} \mathrm{PBS/Matrigel} \mathrm{into} \mathrm{the} \mathrm{left} \mathrm{shoulder.} \mathrm{One}$ week later, $2.5 \times 10^{6}$ PDGFR $\alpha+\beta$ expressing cells also in $100 \mu \mathrm{L} \mathrm{PBS} /$ Matrigel were injected into the right shoulder. This staggered xenograft BCPAP tumour growth timing was required because of the much more rapid growth of BCPAP PDGFR $\alpha(+)$ tumours compared to the xenografts with only PDGFR $\beta$. A doxycycline slow-releasing pellet was implanted into the right flank at the same time. One week later, mice were assigned into separate cages housing control and treatment groups. Tumors were palpable at that time. Mice were treated daily intraperitoneally with $50 \mathrm{mg} / \mathrm{kg}$ imatinib mesylate in $100 \mu \mathrm{L}$ saline, while the control animals received saline i.p. injections only for 6 days. Treatment was repeated with a different set of animals to verify the results and increase the total numbers. For vemurafenib therapy alone, mice were treated daily intraperitoneally with $20 \mathrm{mg} / \mathrm{kg}$ vemurafenib in $85 \mu \mathrm{L} \mathrm{DMSO} /$ saline $(80 / 20 \mathrm{v} / \mathrm{v})$. The combination therapy of vemurafenib and imatinib was commenced as follows: Mice were treated daily intraperitoneally with $30 \mathrm{mg} / \mathrm{kg}$ imatinib mesylate in $85 \mu \mathrm{L}$ saline and $20 \mathrm{mg} / \mathrm{kg}$ vemurafenib in $85 \mu \mathrm{L} \mathrm{DMSO} /$ saline $(80 / 20 \mathrm{v} / \mathrm{v})$, while the control animal received $85 \mu \mathrm{L}$ DMSO/saline $(80 / 20 \mathrm{v} / \mathrm{v})$ for 6 days. The mice underwent PET imaging with $\left[{ }^{18} \mathrm{~F}\right] \mathrm{FDG}$ on the last day of treatment 
(control day 5, treatment group day 6). Tumour sizes were measured using a calliper before and on the last day of therapy. Tumor volumes were calculated from two dimensions and calculated using the formula for the volume: $\mathrm{V}=\left(\mathrm{W}^{2} \times \mathrm{L}\right) / 2$ (Faustino et al. 2013).

\section{In vivo PET imaging}

PET imaging experiments were carried out on an INVEON ${ }^{\circledR}$ PET scanner (Siemens Preclinical Solutions, Knoxville, TN, USA). Mice were anesthetized by inhalation of isoflurane in $40 \% \mathrm{O}_{2} / 60 \% \mathrm{~N}_{2}, 1.5 \mathrm{~L} / \mathrm{min}$, while maintaining body temperature at $37^{\circ} \mathrm{C}$ throughout the experiment. Five to $10 \mathrm{MBq}$ of $\left[{ }^{18} \mathrm{~F}\right] \mathrm{FDG}$ in saline was administered intravenously using a tail vein catheter. Dynamic PET scans were acquired over $1 \mathrm{~h}$ post injection (p.i.). The image files were reconstructed using the maximum a posteriori (MAP) algorithm. The image files were further analysed using the ROVER v 2.0.51 software (ABX GmbH, Radeberg, Germany). Masks for defining 3D regions of interest (ROI) were delineated, and radioactivity in the ROIs was analysed by 50\% thresholding. Mean standardized uptake values $\left(\mathrm{SUV}_{\text {mean }}=(\right.$ activity $/ \mathrm{mL}$ tissue $) /($ injected activity/ body weight), mL/g) were calculated for each ROI.

\section{Western blot analysis of xenograft tumour samples}

Excised xenograft tumours were processed using a gentleMACS $^{\text {тм }}$ Dissociator (Miltenyi Biotec, San Diego, CA, USA) in RIPA buffer (150 mM NaCl, $100 \mathrm{mM}$ Tris (pH 8.0), 1\% Triton X-100, 1\% deoxycholic acid, 0.1\% SDS, $5 \mathrm{mM}$ EDTA, and $10 \mathrm{mM} \mathrm{NaF}$ ) supplemented with $1 \mathrm{mM}$ sodium vanadate, $2 \mathrm{mM}$ leupeptin, $2 \mathrm{mM}$ aprotinin, $1 \mathrm{mM}$ phenylmethylsulfonyl fluoride (PMSF), $1 \mathrm{mM}$ DTT, $2 \mathrm{mM}$ pepstatin, and 1:100 protease inhibitor cocktail set III on ice. After centrifugation at $4^{\circ} \mathrm{C}$ at $35,000 \mathrm{~g}$ for $15 \mathrm{~min}$, the supernatant was harvested as the total soluble protein extract. Protein concentration was determined using Pierce $^{\mathrm{TM}}$ BCA Protein Assay Kit (Pierce Biotechnology). Protein extract samples $(100 \mu \mathrm{g})$ were resolved by SDS-PAGE and transferred to nitrocellulose membrane, blocked in $5 \%$ non-fat milk in TBS containing $0.05 \%$ Tween 20 for 60 min, followed by incubation with primary antibodies at $4^{\circ} \mathrm{C}$ overnight. Protein bands were detected by incubation with horseradish peroxidase-conjugated antibodies (Pierce Biotechnology) and visualized with SuperSignal West Pico chemiluminescence substrate (Thermo Scientific). The following primary antibodies were used: PDGFR $\alpha$ (Cell signaling 5241; dilution 1:1000), p-ERK (Cell Signaling 9106; dilution 1:1000), t-ERK
(Santa Cruz (sc-94; dilution 1:2000) and $\gamma$-tubulin (SigmaAldrich T6557; dilution 1:10,000).

\section{Immunohistochemistry}

Excised xenograft tumour tissues were fixed in neutral buffered $10 \%$ formalin overnight and embedded into paraffin. Slides with $4 \mu \mathrm{m}$ sections were dried at $60^{\circ} \mathrm{C}$ for $1 \mathrm{~h}$ and re-hydrated by three changes of xylene for $10 \mathrm{~min}$ each, then graded ethanol from $100 \%$ to $50 \%$, followed by water and TBS. Slides were microwaved in a pressure cooker for 6 min in citraconic anhydride $(0.05 \%$ in water, $\mathrm{pH} 7.4)$ for antigen retrieval and blocked with $0.5 \%$ fish gelatin in Tris-buffered saline with $0.05 \%$ Tween 20 (TBST) for $30 \mathrm{~min}$ and incubated with mouse monoclonal anti-GLUT1 IgG1 (clone A-4, sc-377228, Santa Cruz Biotechnology, 1:50) or mouse monoclonal anti-HK-2 IgG1 (ab-37593, Abcam PLC Biotechnology, 1:50) in a humidity chamber overnight at $4^{\circ} \mathrm{C}$. After incubation in $3 \% \mathrm{H}_{2} \mathrm{O}_{2}$ in water for 15 min, slides were incubated with DakoCytomation Envision+ anti-mouse or anti-rabbit labelled Polymer HRP (DakoCytomation) for $1 \mathrm{~h}$, developed, using Dako Liquid $\mathrm{DAB}+$ Substrate Chromagen System and 1\% copper sulphate and counterstained with hematoxylin. Slides were dehydrated by reversing rehydration and cover-slipped. Negative controls were prepared without primary antibodies. Quantification analysis of protein expression was carried out with Image J 1.x (NIH and LOCI, University of Wisconsin, Madison, WI, USA) and IHC profiler (Varghese et al. 2014).

\section{Kinetic modelling}

The dynamic PET data sets were analysed as previously described using a reversible two-compartment catenary model with blood volume parameter (Van den Hoff 2005, Prenen et al. 2006, Jans et al. 2018). For this purpose, an ROI defining the vena cava was generated by thresholding averaged early time frames (8-20 s p.i.) that visualized the initial bolus blood flow. The plasma input time-activity curves (TAC) generated from this ROI were convolved with the impulse response of the compartmental model and numerically fitted to the tumor-derived TAC of the same animal. This procedure was implemented in Mathlab software (version R2018a), utilizing a NelderMead simplex direct search. The fit was governed by the minimization of a cost function sensitive to the difference between measured values and those predicted by the model and the goodness of fit was determined by its $R^{2}$ value. 


\section{Statistical analysis}

All in vitro data, semi-quantified PET as well as quantified protein expression data are expressed as mean \pm s.E.M. Graphs and time-activity curves (TAC) were constructed using GraphPad Prism 5.0 (GraphPad Software). Statistical differences were tested by Student's $t$-test and were considered significant for $\left.P<0.05\left(^{*}\right), P<0.01{ }^{(*}\right)$ and $\left.P<0.001{ }^{(* *}\right)$.

\section{Results}

\section{In vitro studies}

The BRAFV600E mutated thyroid cancer BCPAP cell line, both mock and PDGFR $\alpha$ transfected, showed a strong [18F] FDG in vitro cell uptake reaching $522 \pm 23$ in PDGFR $\beta$ and $569 \pm 25 \%$ radioactivity $/ \mathrm{mg}$ protein in PDGFR $\alpha+\beta$ BCPAP cells after $120 \mathrm{~min}$ (Fig. 1A). This is consistent with the known strong dependence on glycolysis of the parental cell line (Coelho et al. 2016). Protein expression of PDGFR $\alpha$ has significant effects on cell morphology,
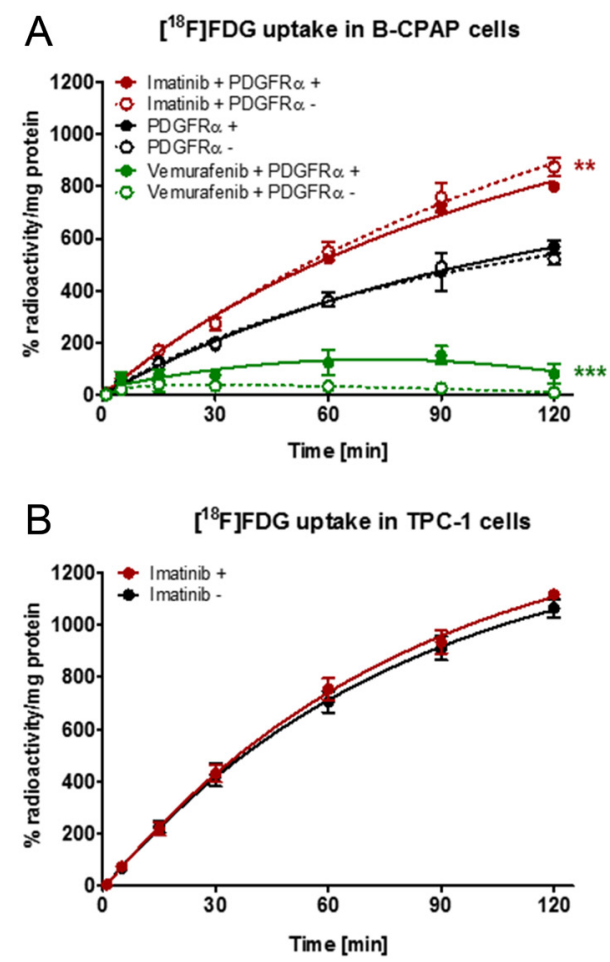

Figure 1

In vitro cell uptake data for radiotracers. (A) Effect of 48-h imatinib $(0.3 \mu \mathrm{M})$ and vemurafenib $(0.25 \mu \mathrm{M})$ treatment on [ $\left.{ }^{18} \mathrm{~F}\right] \mathrm{FDG}$ uptake into PDGFR $\alpha(+)$ and PDGFR $\alpha(-)$ B-CPAP cells treated with PDGF-AA $(50 \mathrm{ng} / \mathrm{mL})$. (B) Effect of 48 -h long imatinib $(0.3 \mu \mathrm{M})$ treatment on [18F]FDG uptake into WT BRAF TPC-1 cells. Data shown as \% radioactivity/mg protein and as mean \pm S.E.M. from three experiments performed as triplicates. $* * P<0.01$ and $* * * P<0.001$.

(c) 2020 Society for Endocrinology Published by Bioscientifica Ltd. Printed in Great Britain the epithelial-mesenchymal transition and xenograft tumour growth, but minimal influence on basic cellular [18F]FDG uptake (22-24). Surprisingly, a low dose treatment with $0.3 \mu \mathrm{M}$ imatinib over $48 \mathrm{~h}$ increased the $\left[{ }^{18} \mathrm{~F}\right] \mathrm{FDG}$ uptake in vitro by nearly $70 \%$ to $874 \pm 36 \%$ radioactivity/mg protein $(P<0.01)$ in PDGFR $\beta$ cells at 120 min while having minimal effect on cell count. In contrast, in a control experiment using the TPC1 thyroid cancer cell line lacking BRAFV600E, imatinib treatment had no significant effect on the [18F]FDG uptake with $1064 \pm 41$ (no imatinib) and $1117 \pm 41 \%$ radioactivity $/ \mathrm{mg}$ protein (with $0.3 \mu \mathrm{M}$ imatinib) at $120 \mathrm{~min}$ (Fig. 1B). In contrast to the effects of imatinib treatment of PDGFR $\alpha+\beta$ and PDGFR $\beta$ BCPAP cells, treatment with $0.25 \mu \mathrm{M}$ vemurafenib, an ATP competitive inhibitor targeting BRAFV600E, strongly decreased in vitro cell uptake of [18F]FDG; $10 \pm 1$ in PDGFR $\beta$ and $81 \pm 38 \%$ radioactivity/ mg protein $(P<0.001)$ in PDGFR $\alpha+\beta$ BCPAP cells after 120 min (Fig. 1A). Taken together, blocking PDGFR with imatinib leads to a strong increase in glucose metabolic demand, while blocking BRAFV600 with vemurafenib strongly reduces glucose energy metabolism in BCPAP cells. PDGFR $\alpha$ expression in these cells had no influence on glucose demand. Similar to the results with $\left[{ }^{18} \mathrm{~F}\right]$ FDG, there was also no influence of PDGFR $\alpha$ expression on $\left.{ }^{18}{ }^{18} \mathrm{~F}\right] \mathrm{FLT}$ cell uptake (data not shown) indicating that proliferation rate was not influenced by PDGFR $\alpha$.

\section{In vivo PET imaging}

Mouse xenografts bearing bilateral PDGFR $\beta$ or $\alpha+\beta$ transfected BCPAP tumours were analysed with $\left[{ }^{18} \mathrm{~F}\right]$ FDG PET. Figure 2 shows representative PET images at 60 min p.i. of [18F] FDG (Fig. 2A), the dynamic uptake profile over $60 \mathrm{~min}$ in tumour tissue and non-targeting

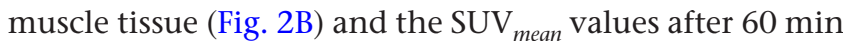
p.i. for visualization of the quantitative differences for each measured condition (Fig. 2C). Both, PDGFR $\beta$ and PDGFR $\alpha+\beta$ tumours showed similar uptake levels and profiles over time reaching similar SUV values after $60 \mathrm{~min}$ p.i.: $1.88 \pm 0.07$ in PDGFR $\beta$ and $1.85 \pm 0.14$ in PDGFR $\alpha+\beta$ tumours $(n=13)$. After 6 days of imatinib therapy (50 $\mathrm{mg} / \mathrm{kg}$ daily), $\left.{ }^{18} \mathrm{~F}\right] \mathrm{FDG}$ uptake was significantly increased in both tumours with a higher uptake in PDGFR $\alpha+\beta$ tumours: $\mathrm{SUV}_{\text {mean,60 min }} 2.42 \pm 0.11(n=9 ; P<0.001)$ in PDGFR $\beta$ and $2.69 \pm 0.28(n=9 ; P<0.01)$ in PDGFR $\alpha+\beta$. In contrast, 6 days of a single vemurafenib therapy (20 $\mathrm{mg} / \mathrm{kg}$ daily) strongly reduced $\left[{ }^{18} \mathrm{~F}\right] \mathrm{FDG}$ tumour uptake: $\mathrm{SUV}_{\text {mean,60min }} 0.94(n=2)$ in PDGFR $\beta$ and $1.04 \pm 0.14$ $(n=4 ; P<0.01)$ in PDGFR $\alpha+\beta$. The effect of combination 

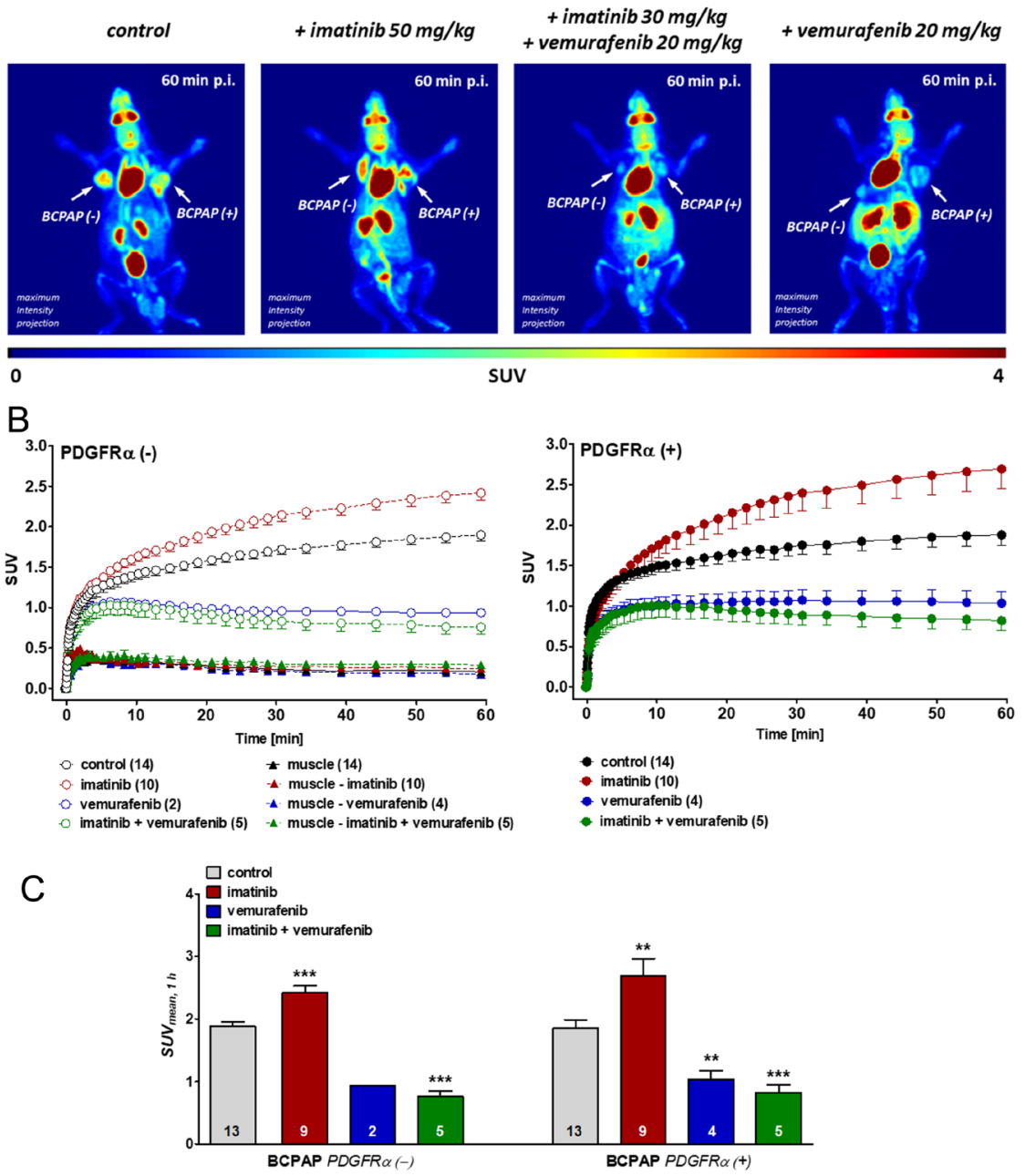

Figure 2

PET imaging using [18F]FDG in NSG xenografts bearing PDGFR $\alpha$ (+; right side) and PDGFR $\alpha$ (-; left side) B-CPAP tumours. (A) Representative images as maximum intensity projection after $60 \mathrm{~min}$ post injection for control animals injected with saline only (left), imatinib-treated mice $(50 \mathrm{mg} / \mathrm{kg}$ for 6 days; middle left), under combination therapy of imatinib/vemurafenib $(30 \mathrm{mg} / \mathrm{kg}+20$ $\mathrm{mg} / \mathrm{kg}$; middle right) and vemurafenib $(20 \mathrm{mg} / \mathrm{kg}$ ) therapy alone (right). (B) Time-activity curves (TACs) over 60 min dynamic experiments for [18F]FDG tumour (PDGFR $\alpha$ (-) - (left) and PDGFR $\alpha$ $(+)$ - (right)) as well as non-targeting muscle tissue uptake under the same therapy conditions as mentioned previously. (C) Effects of imatinib, vemurafenib and combination therapy imatinib/vemurafenib on SUV $\mathrm{Vean}_{\text {values at }} 60 \mathrm{~min}$ p.i. Data shown as SUV $V_{\text {mean }}$ and mean \pm S.E.M. from $n$ experiments. $* * P<0.01$ and $* * * P<0.001$ vs control.

therapy using vemurafenib (20 mg/kg daily) and imatinib (30 $\mathrm{mg} / \mathrm{kg}$ daily) led to a similar significant reduction of [18F]FDG uptake: $\mathrm{SUV}_{\text {mean,60min }} 0.76 \pm 0.20(n=5 ; P<0.001)$ in PDGFR $\beta$ and $0.82 \pm 0.12(n=5 ; P<0.001)$ in PDGFR $\alpha+\beta$. Uptake of $\left[{ }^{18} \mathrm{~F}\right] \mathrm{FDG}$ into non-targeting reference muscle tissue was not influenced by any therapeutic condition at all (Fig. 2B). Thus, results on glucose uptake and metabolism in xenograft tumours in vivo were consistent with the effects measured in BCPAP cells in vitro. This may be related to altered pERK signalling with PDGFR blockade, as shown in Fig. 3. Imatinib disruption of PDGFR induces changes in ERK signalling with appearance of the 50-kDa ERK isoform, first characterized by Ben-David et al. (2006), in both PDGFR $\alpha$ and PDGFR $\alpha+\beta$ tumours. All xenografts clearly demonstrate this alternatively spliced ERK form (Ben-David et al. 2006). Metabolic remodelling and altered ERK signalling pathway was previously seen altered in PDGFR and AKT pathway function shown by
Ekpe-Adewuyi et al. (2016). Sabbatino et al. (2014) also demonstrates PDGFR $\alpha$ and ERK signalling that mediates response to BRAF inhibitors. The absence of BRAF, or BRAF blockade, prevents reprogramming of glucose metabolism in our preclinical tumour model.

\section{Tyrosine kinase inhibitor therapy effect on tumour growth}

[18F]FDG tumour uptake was also correlated to xenograft tumour growth in all differently treated groups. Due to the substantially increased growth rate for PDGFR $\alpha+\beta$ tumours, a shorter lead growth time was used compared to tumours with only PDGFR $\beta$. Figure 4 depicts the tumour sizes for PDGFR $\beta$ and PDGFR $\alpha+\beta$ tumours for imatinib therapy alone (Fig. 4A), single vemurafenib therapy (Fig. 4B) and combination therapy of imatinib and vemurafenib (Fig. 3C) before and after 6 days of therapy, at which time the 


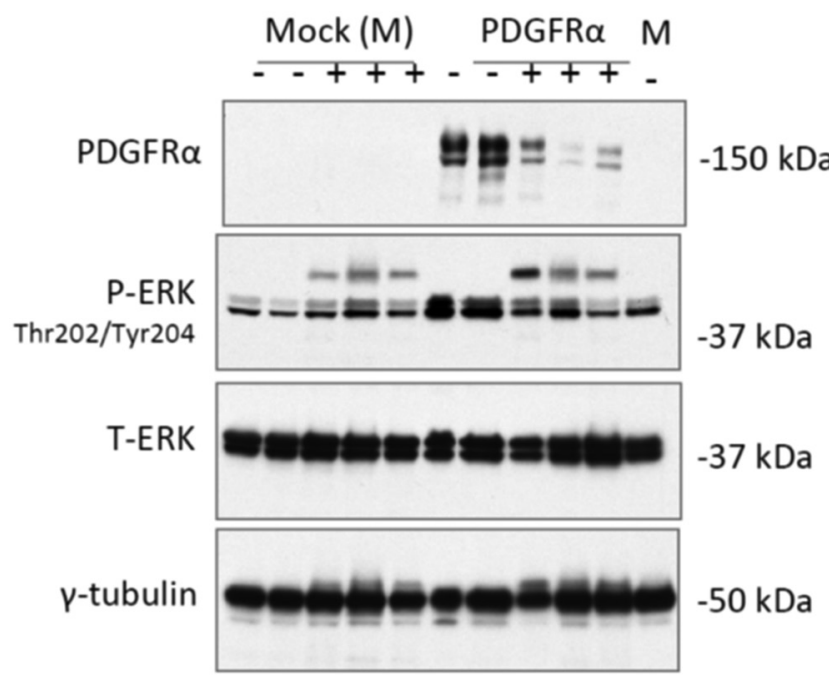

Figure 3

Western blots for analysis of PDGFR $\beta$ and PDGFR $\alpha+\beta$ expressing BCPAP tumour tissue samples from NSG mice receiving either $50 \mathrm{mg} / \mathrm{kg}$ imatinib for 6 days (+) or control vehicle injections (-).

PET experiments were performed. Imatinib therapy alone was not effective in reducing tumour growth in both (PDGFR $\beta$ and $\alpha+\beta$ ) therapy groups vs the control groups. However, single therapy using vemurafenib led to a tendency of tumour growth reduction, while combination therapy of imatinib and vemurafenib was strikingly effective at reducing tumour burdens in both PDGFR $\beta$ and PDGFR $\alpha+\beta$ tumours by nearly $90 \%: 121 \pm 23 \mathrm{~mm}^{3}$ (control group) vs $16 \pm 6 \mathrm{~mm}^{3}$ ( $P<0.01$, therapy group) for PDGFR $\beta$ only and $209 \pm 54 \mathrm{~mm}^{3}$ (control group) vs $29 \pm 6 \mathrm{~mm}^{3}$ $(n=5, P<0.01$, therapy group) for PDGFR $\alpha+\beta$.

\section{Kinetic modelling of [18F]FDG tumour uptake}

Kinetic modelling was used to analyse the uptake of $\left[{ }^{18} \mathrm{~F}\right]$ FDG into BCPAP tumours using a standard, reversible two compartment model. Figure 5 displays analysed factors $\mathrm{k}_{1}$ to $k_{4}$ and the ratios $k_{3} /\left(k_{2}+k_{3}\right)$ as well as $K_{1} \cdot k_{3} /\left(k_{2}+k_{3}\right)$ for both PDGFR $\beta$ (Fig. 5A) and PDGFR $\alpha+\beta$ (Fig. 5B) tumours. $\mathrm{K}_{1}$ and $\mathrm{k}_{2}$ were found to be similar and not significantly changed by any therapeutic intervention through all analysed thyroid tumours except some slight increases only in PDGFR $\alpha+$ tumours under single vemurafenib therapy. These two factors, $K_{1}$ and $k_{2}$, quantify tracer transport through the active cell membrane, mainly by GLUT1, resulting in radiotracer tissue uptake. Factor $k_{3}$ represents the hexokinase-II mediated phosphorylation rate and did increase significantly for both BCPAP tumours: from $0.08 \pm 0.011 / \mathrm{min}$ to $0.15 \pm 0.031 / \mathrm{min}(P<0.01)$ for PDGFR $\alpha+\beta$ tumours. Conversely both, individual blockade of BRAF with vemurafenib, and combination therapy, strongly reduced $k_{3}$ in PDGFR $\alpha+\beta$ tumours: for vemurafenib $0.05 \pm 0.011 / \mathrm{min}(P<0.092)$ and for combination therapy $0.02 \pm 0.0041 / \mathrm{min}(P<0.01)$ vs $0.08 \pm 0.01$ in control tumours. While the dephosphorylation rate $\mathrm{k}_{4}$ was not changed with imatinib, single therapy with vemurafenib as well as combination therapy with both drugs increased it significantly from $0.013 \pm 0.0011 / \mathrm{min}$ to $0.028 \pm 0.0061 / \mathrm{min}(P<0.01$; vemurafenib alone $)$ and $0.046 \pm 0.0021 / \mathrm{min} \quad(P<0.01$; combination therapy $)$ in PDGFR $\alpha+$ tumours. Taken together, imatinib led to increased phosphorylation, while vemurafenib reduced phosphorylation and increased de-phosphorylation of [18F]FDG. The ratio $k_{3} /\left(k_{2}+k_{3}\right)$ quantifies the fraction of radiotracer being shunted from the first into the second compartment phosphorylation, and this was increased under imatinib therapy in xenograft tumours from $0.29 \pm 0.021 / \mathrm{min}(n=13)$ to $0.51 \pm 0.081 / \mathrm{min}(P<0.01)$, but was strongly reduced by single therapy of vemurafenib resulting in $0.14 \pm 0.021 / \mathrm{min} \quad(n=4 ; P<0.05)$ or combination therapy to $0.17 \pm 0.031 / \mathrm{min}(n=5 ; P<0.01)$,

A Therapy with imatinib $(50 \mathrm{mg} / \mathrm{kg}$ daily)
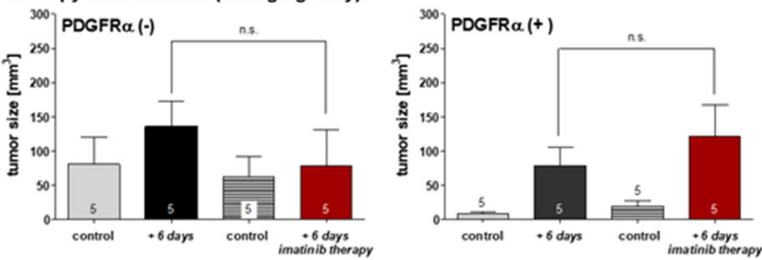

B Therapy with vemurafenib $(20 \mathrm{mg} / \mathrm{kg}$ daily)
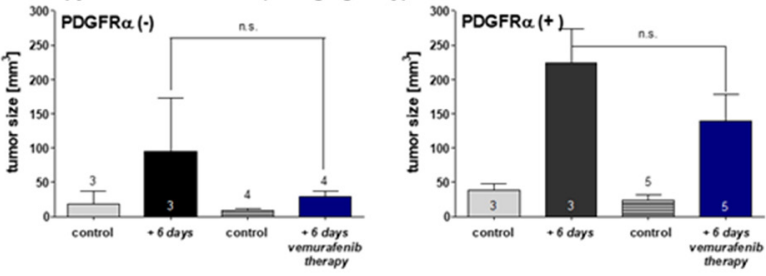

C Combination therapy with imatinib $(30 \mathrm{mg} / \mathrm{kg}$ daily) and vemurafenib $(20 \mathrm{mg} / \mathrm{kg}$ daily)
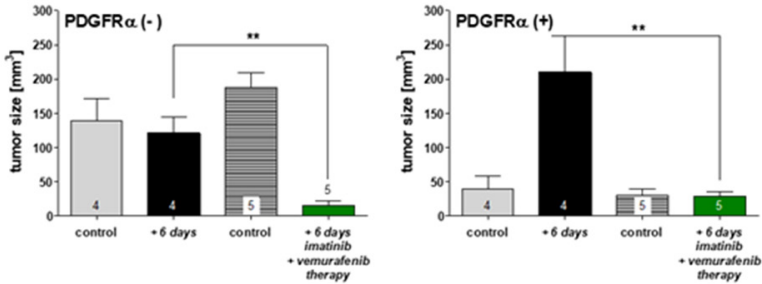

\section{Figure 4}

Effect of therapeutic interventions on tumour sizes under the different conditions before therapy (control bars) and after 6 days of therapy (as indicated). (A) Single imatinib therapy (50 mg/kg), (B) single vemurafenib therapy $(20 \mathrm{mg} / \mathrm{kg})$ and $(C)$ combination therapy $(30 \mathrm{mg} / \mathrm{kg}$ imatinib +20 $\mathrm{mg} / \mathrm{kg}$ vemurafenib). Data shown as SUV mean and mean \pm S.E.M. from $n$ experiments. ** $P<0.01$ and $* * * P<0.001$. (c) 2020 Society for Endocrinology Published by Bioscientifica Ltd. Printed in Great Britain 
$\left[{ }^{18} \mathrm{~F}\right] F D G$ - PDGFR $\alpha(-)$
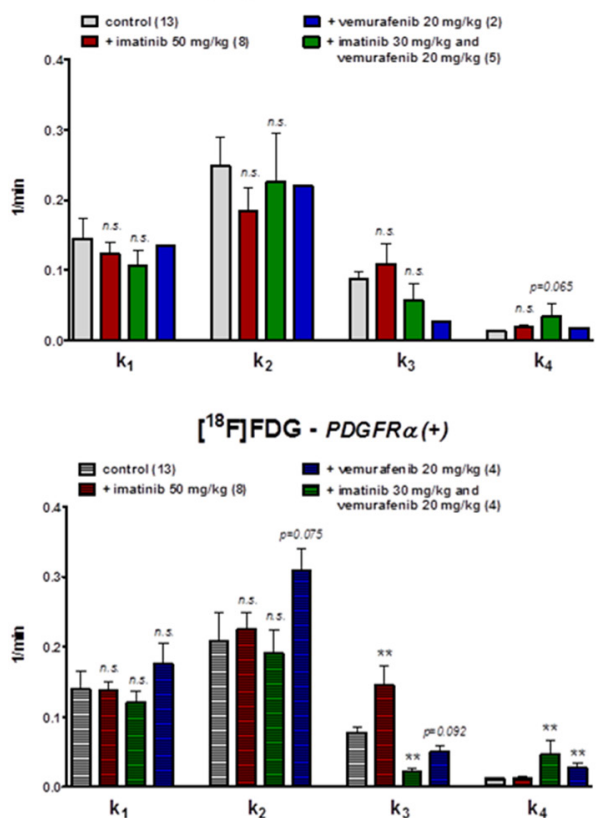

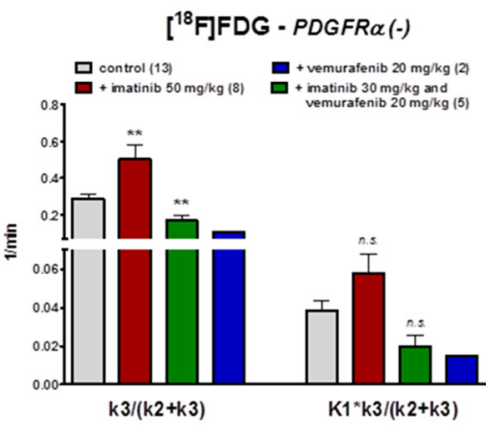

$\left[{ }^{18}\right.$ F]FDG - PDGFR $\alpha(+)$

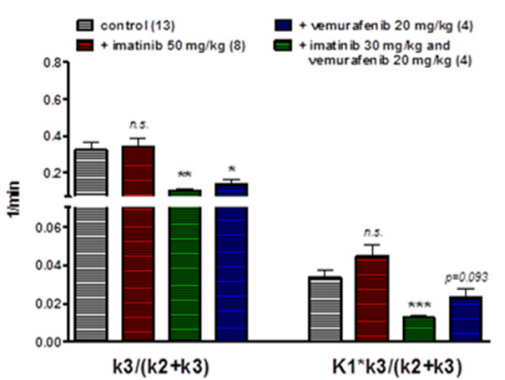

Figure 5

Apparent tumor kinetic parameters $\mathrm{K}_{1}$ to $\mathrm{k}_{4}$ and ratios $\mathrm{k}_{3} /\left(\mathrm{k}_{2}+\mathrm{k}_{3}\right)$ and $\mathrm{K}_{1} \cdot\left(\mathrm{k}_{3} /\left(\mathrm{k}_{2}+\mathrm{k}_{3}\right)\right)$ for $\left[{ }^{18} \mathrm{~F}\right] \mathrm{FDG}$ tumor uptake as derived from a twocompartment model. Effects of single therapy with imatinib (red) or vemurafenib (blue) and combination therapy of imatinib/vemurafenib (green) are shown. Top, PDGFR $\alpha$ (-) B-CPAP tumours; Bottom, PDGFR $\alpha(+)$ B-CPAP tumours. Data shown as mean \pm S.E.M. from $n$ experiments. $* P<0.05, * * P<0.01, * * * P<0.001$ vs control. respectively. The quotient $\mathrm{K}_{1}{ }^{*} \mathrm{k}_{3} /\left(\mathrm{k}_{2}+\mathrm{k}_{3}\right)$ then represents the absolute 'trapping' (phosphorylation) rate $(\mathrm{mL} / \mathrm{min}$ per $\mathrm{mL}$ tissue), which was increased in the presence of imatinib, but significantly decreased when vemurafenib was added in a single or combination therapy (see also Fig. 2). Overall, there was no pronounced effect of PDGFR $\alpha$ expression on the $\left[{ }^{18} \mathrm{~F}\right] \mathrm{FDG}$ tracer kinetic profile in vivo.

\section{GLUT1 and hexokinase II protein expression}

Immunohistochemistry revealed a baseline expression of GLUT1 (Fig. 6) and hexokinase-2 (HK-II) in untreated tumours (Fig. 7). Quantified protein positive staining showed single imatinib treatment led to a significant increase of GLUT1 expression (Fig. 6) in vivo: from $39.2 \pm 3.8 \%$ to $61.2 \pm 1.4 \%(n=3 ; P<0.01)$ in PDGFR $\beta$ tumours. Combination therapy with vemurafenib resulted in reduced GLUT1 expression which was closer to the control tumour levels: $50.0 \pm 0.8 \%$ ( $n=3$; n.s. vs controls). In contrast, hexokinase- 2 protein expression (Fig. 7) tended to increase by single imatinib therapy but was significantly reduced during combination therapy with vemurafenib: $56.7 \pm 4.6 \%$ in controls vs $67.6 \pm 9.4 \%$ (imatinib; $n=3$; n.s.) and $33.6 \pm 4.9 \%$ (imatinib+vemurafenib; $n=3 ; P<0.05$ ) all

\section{GLUT-1}
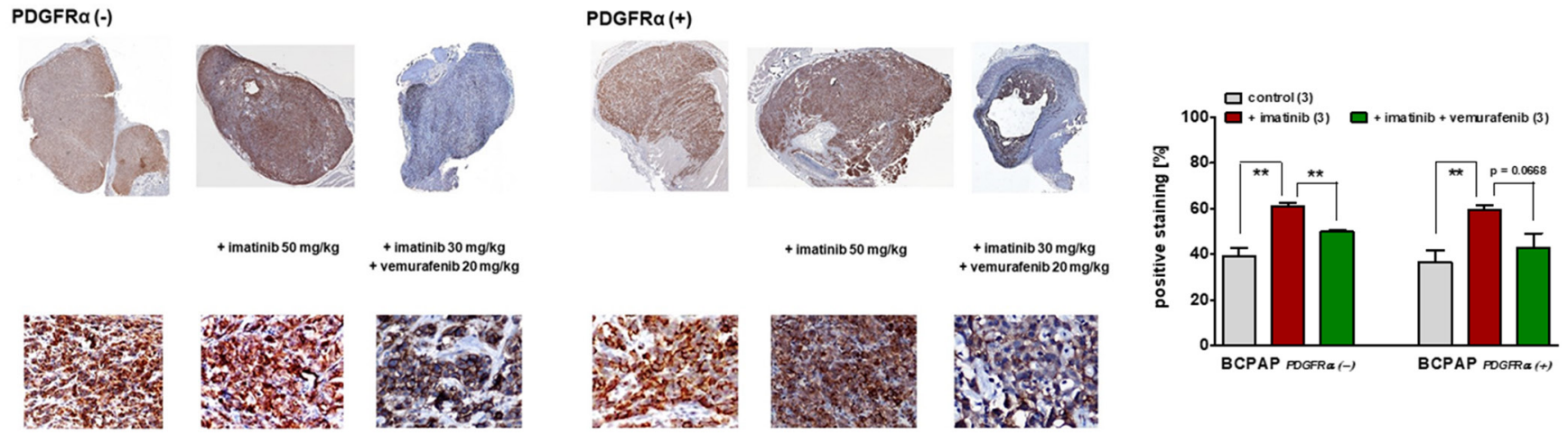

Figure 6

Representative immunohistochemical staining of GLUT1 in PDGFR $(-)$ and PDGFR $\alpha(+)$ tumour slices under control (left), single imatinib therapy ( $50 \mathrm{mg} / \mathrm{kg}$ for 6 days; middle) and combination therapy (30 mg/kg imatinib and $20 \mathrm{mg} / \mathrm{kg}$ vemurafenib for 6 days; right) conditions. (left) Original magnification of the entire tumor slice, $\times 5$, and enlarged areas at higher power, $\times 40$ from the same sample slices; (right) Quantification of positive GLUT1 immunohistochemical staining. Data as mean \pm s.E.M. from $n=3$ slices, $* P<0.05, * * P<0.01$. 


\section{HK-II}

PDGFRa (-)
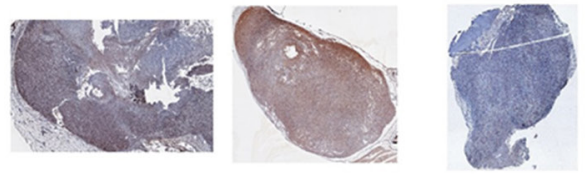

+ imatinib $50 \mathrm{mg} / \mathrm{kg}$
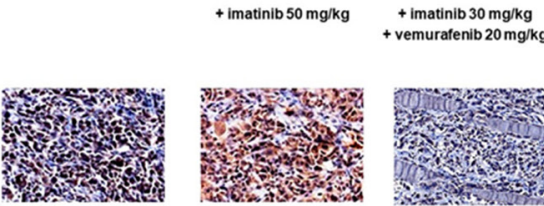
+ vemuratenib $20 \mathrm{mg} / \mathrm{kg}$

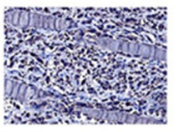

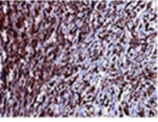
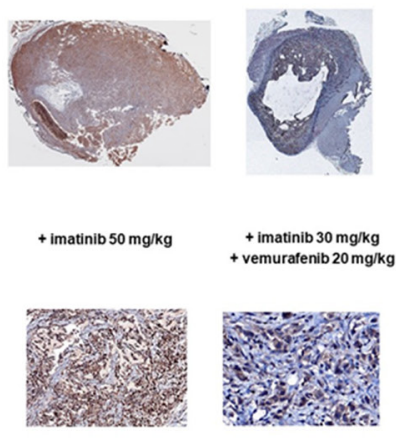

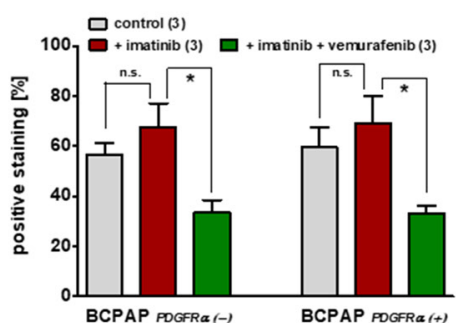

BCPAP PDGFRa (+)

\section{Figure 7}

Representative immunohistochemical staining of hexokinase-2 in PDGFR $\alpha(-)$ and PDGFR $\alpha(+)$ tumour slices under control (left), single imatinib therapy ( $50 \mathrm{mg} / \mathrm{kg}$ for 6 days; middle) and combination therapy ( $30 \mathrm{mg} / \mathrm{kg}$ imatinib and $20 \mathrm{mg} / \mathrm{kg}$ vemurafenib for 6 days; right) conditions. (left) Original magnification of the entire tumor slice, $\times 5$, and enlarged areas at higher power, $\times 40$ from the same sample slices; (right) Quantification of positive hexokinase-2 (HK-II) immunohistochemical staining. Data as mean \pm S.E.M. from $n=3$ slices, ${ }^{\star} P<0.05, * \star P<0.01$.

in PDGFR $\beta$ tumours, respectively. Protein expression data were consistent with our metabolic modelling analysis. Imatinib therapy alone increased uptake and trapping of glucose derivative $\left[{ }^{18} \mathrm{~F}\right] \mathrm{FDG}$. In contrast, combination therapy with vemurafenib led to a strong reduction of metabolic trapping indicating that reduced expression of hexokinase-2 was responsible for that. However, PDGFR $\alpha$ protein expression did not influence GLUT1 and hexokinase- 2 expression.

\section{Discussion}

The present results reveal that the BRAF mutation enables metabolic re-modelling in thyroid cancer xenografts. The main findings are: (1) Tyrosine kinase receptor blockade of PDGFR with imatinib induced a strong increase in metabolic energy demand, possibly through the ERK pathway, as measured with the radioactive glucose derivative [ $\left.{ }^{18} \mathrm{~F}\right] \mathrm{FDG}$; (2) vemurafenib, targeting BRAFV600E, leads to a significant reduction in metabolic glucose demand in the same cell model; (3) in vivo imatinib therapy induced a strong increase in metabolic glucose demand of BCPAP tumours as measured with [18F]FDG, while single vemurafenib therapy resulted in the opposite, a significant reduction of $\left[{ }^{18 F}\right]$ FDG uptake; (4) when imatinib and vemurafenib were combined also a strong reduction of energy metabolism and dramatic decreases in xenograft tumor growth occurred; and (5) the effect of imatinib on BCPAP energy metabolism maybe due to stronger upregulation of hexokinase-2 enzyme rather than GLUT1 transporters as detected with immunohistochemistry and analyzed with kinetic modelling.

(c) 2020 Society for Endocrinology Published by Bioscientifica Ltd. Printed in Great Britain
PDGFR-targeting tyrosine kinase inhibitor imatinib binds both PDGFR $\alpha$ and PDGFR $\beta$ (Valerio et al. 2017). Imatinib treatment increased [18F]FDG uptake in both PDGFR $\alpha$ positive and negative cell lines significantly. PDGFR $\alpha$ expression does not appear to play any additional role for imatinib-induced effects on glycolytic energy metabolism in BCPAP cells. By blocking PDGFR and/or c-Kit in BCPAP cells, the glycolysis pathway seems to be upregulated. This is contrary to reports in other studies using imatinib as chemotherapeutic drug for gastrointestinal stromal tumors (GISTs) (Van den Abbeele et al. 2012). A comprehensive review of clinical studies confirmed that imatinib therapy initially reduces [18F]FDG uptake by up to $40 \%$ in GIST tumours; however, after further c-KIT mutations under long-term therapeutic observations, this is abrogated (Treglia et al. 2012). Vemurafenib significantly reduced $\left[{ }^{18} \mathrm{~F}\right]$ FDG uptake in both PDGFR $\beta$ and PDGFR $\alpha+\beta$ cell lines. Vemurafenib blocks c-Kit/PDGFR downstream target BRAFV600 mutation directly. This indicates that c-Kit/PDGFR blocking with imatinib induces the increased energy metabolism through BRAFV600E mutated BCPAP cells, while blockade of BRAFV600E leads to downregulation of glucose uptake and metabolism in these cells. This metabolic remodelling has been seen before in melanoma and colorectal cancer cells (Hutton et al. 2016, Lee et al. 2016). In vitro control experiments with imatinib in TPC1 cells, expressing WT BRAF, did not lead to any increased [18F]FDG uptake. Therefore, it appears that the BRAFV600E mutation is indeed a key target for glycolytic metabolism in BCPAP thyroid cancer cells. BRAFV600E mutation and [18F]FDG avidity have already been linked in PTC (Santhanam et al. 2018). These studies support the 
conclusion that metabolic remodelling in thyroid cancer as a consequence of chemotherapy may be monitored using non-invasive $\left[{ }^{18} \mathrm{~F}\right]$ FDG-PET.

BRAFV600E mutation and $\left[{ }^{18} \mathrm{~F}\right] \mathrm{FDG}$ avidity have already been linked in PTC (Nagarajah et al. 2015, Ferretta et al. 2016, Hutton et al. 2016, Lee et al. 2016). Lee et al. have shown that thyroid cancer patients with BRAF $600 \mathrm{E}$ mutation showed higher [18F]FDG uptake than thyroid cancers without it (Lee et al. 2016). Yoon et al. confirmed these findings and reported that $~ 65 \%$ of PTC patients carried the BRAFV600E mutation (Yoon et al. 2016). And a recent review by Ciavardelli et al. summarized numerous clinical studies revealing a link between GLUT1 transporters and hexokinase-2 among other downstream targets with BRAFV600E mutation in thyroid cancer (Ciavardelli et al. 2017). Analysis of single therapy with imatinib and combination therapy with imatinib and vemurafenib in B-CPAP xenograft model in vivo resulted in similar effects as detected in vitro. Glucose energy metabolism was turned on with c-Kit/PDGFR blockade using imatinib, while addition of BRAFV600E mutation targeting vemurafenib resulted in a strong downregulation of energy metabolism as detected with [18F]FDG PET. Clinical studies in melanoma patients have described complete metabolic response of vemurafenib on [18F]FDG uptake (Pascal et al. 2018). Parmenter et al. have shown that BRAF inhibition in BRAF-mutant melanoma is mediated by a network of transcriptional regulators of glycolysis including hypoxia-inducible factor $1 \alpha$ (HIF-1 $\alpha$ ) following downstream targets GLUT1 and 3 as well hexokinase-2 (Parmenter et al. 2014). This confirms that the pro-oncogene BRAFV600E regulates downstream glucose energy metabolism as can be assessed with $\left[{ }^{18} \mathrm{~F}\right] \mathrm{FDG}$ functional analysis. Reports in BCPAP cell line and clinical specimens have also linked pyruvate kinase $\mathrm{M} 2$, a glucose metabolism protein, with the BRAFV600E mutation (Feng et al. 2013).

In contrast to previous studies, the present work demonstrates that it is likely hexokinase II upregulation that confers this tumour phenotype and not changes in GLUT 1 expression (Yoon et al. 2016). Baseline levels of GLUT1 expression may vary based on BRAFV600E; however, compartmental analysis demonstrates that the intracellular trapping levels in BCPAP tumours are governed by the phosphorylation rate and hexokinase- 2 activity. Imatinib therapy alone led to an increase in phosphorylation as expressed in the ratio $\mathrm{k} 3 /(\mathrm{k} 2+\mathrm{k} 3)$, as well as increase in the absolute 'trapping' rate $\mathrm{K} 1 \cdot \mathrm{k} 3 /(\mathrm{k} 2+\mathrm{k} 3)$, pointing to functional upregulation of hexokinase-2 enzyme activity. Single vemurafenib therapy or in combination with imatinib both led to the opposite: reduced phosphorylation rates and a strong suppression of 'trapping'. Kinetic analysis confirmed no significant change of $\mathrm{K}_{1}$ and $\mathrm{k}_{2}$ under any treatment regimen, indicating that $\left[{ }^{18} \mathrm{~F}\right] \mathrm{FDG}$ uptake, facilitated mainly through GLUT1 transporters, may not be substantially altered by blocking the BRAFV600E mutation. Moreover, the immunohistochemistry clearly demonstrates in the xenograft tumour samples that a significantly increased expression of hexokinase- 2 occurs. These results therefore point towards the regulation of hexokinase-2, rather than GLUT1 transporter, through the thyroid mutated oncogene BRAFV600E. Blocking of PDGFR $\alpha+\beta$ leads to changes in ERK and, further downstream, the increase of hexokinase-2 expression resulting in higher metabolic glucose demand as measured with [18F]FDG. Changes in pERK levels and altered ERK isofroms have been documented previously with our work on changes in PDGFRA signalling and blockade (Ekpe et al. 2016), as well as by Ben-David et al. (2006) and Sabbatino et al. (2014). The relationship between ERK signalling and [18F]FDG uptake has also been well documented in clinical analysis of MEK inhibitors in different metastatic solid tumours, whereby decreased ERK activity follows a reduction in [18F]FDG uptake (Kraeber-Bodéré et al. 2012).

[18F]FDG-PET functional analysis of BRAFV600E thyroid carcinomas may be a useful adjunct to directed therapy for advanced disease. Clinical studies in melanoma patients have described complete metabolic response of vemurafenib based on [18F]FDG uptake (Pascal et al. 2018). Parmenter et al. have shown that BRAF inhibition in BRAF-mutant melanoma is mediated by a network of transcriptional regulators of glycolysis including hypoxia-inducible factor $1 \alpha$ (HIF-1 $\alpha$ ) following downstream targets GLUT1 and hexokinase-2, similar to what we observed in our xenografts (Parmenter et al. 2014). Inhibition of BRAF ${ }^{\mathrm{V} 600 \mathrm{E}}$ strongly reduces tumour size and uptake of glucose derivative [18F]FDG, while PDGFR inhibition by imatinib paradoxically increases glycolysis based on upregulation of hexokinase-2 protein levels. While PDGFR $\alpha$ expression correlates with the metastatic potential in PTC, it appears that it is not a driver for glycolysis in thyroid cancer cells. However, it is important to note that Sabbatino et al. discovered that PDGFR $\alpha$ up-regulation, MAPK reactivation and PI3K/AKT activation lead to BRAF inhibitor resistance in melanoma cells (Sabbatino et al. 2014). The authors suggested that monitoring patients for early PDGFR $\alpha$ up-regulation will facilitate the identification of those who may benefit from the treatment with BRAF inhibitor in combination with 
clinically approved PDGFR $\alpha$ inhibitors. It remains to be elucidated in clinical studies if this would be also the case for the therapy of PTC patients using the various multitargeting TKI developed over the past two decades.

Short-term imatinib therapy of 6 days induced changes in GLUT 1 and hexokinase- 2 protein expression in BCPAP tumours in vivo. Upregulation of protein expression was more pronounced for GLUT1 than hexokinase-2. This finding points to an increased glucose metabolism in BCPAP thyroid cancer cells, which is contradictory to studies in other cancers where TKI therapy led to a reduced energy metabolism detected by [18F]FDG (Vercellino et al. 2009, Ueno et al. 2012, Van den Abbeele et al. 2012, Ma et al. 2017). Short-term imatinib therapy in GIST leads to reduction of $\left.{ }^{18}{ }^{18} \mathrm{~F}\right] \mathrm{FDG}$ uptake and retention (Prenen et al. 2006, Revheim et al. 2011). However, GIST cells can adopt and change their metabolic energy supply leading to imatinib resistance (Vitiello et al. 2018). Comparing to studies using TKI sorafenib, which also targets c-Kit and PDGFR but in addition also VEGFR, glucose metabolism is also strongly reduced in colorectal cancer model HCT116 (Tseng et al. 2017). Similar to sorafenib, TKI sunitinib, which targets similar proteins except Raf, also leads to reduction of [18F]FDG uptake after 6 days treatment in this case in breast cancer (Thézé et al. 2015). However, GLUT1 is upregulated under sunitinib therapy. Thus targeting VEGFR, c-Kit, PDGFR and RET, as well as BRAF, may lead to GLUT 1 upregulation and a downregulation of the overall glucose energy metabolism, as shown here. Only increases in hexokinase-2 expression as detected with imatinib resulted in a 'switch-on' of glucose consumption in BRAFV600E mutated BCPAP cells confirming BRAFV600E as the key-oncogene for energy metabolism as discussed previously.

\section{Conclusions}

The pro-oncogene BRAFV600E is the glycolytic driver in BCPAP thyroid cancer cells. Inhibition of BRAFV600E strongly reduces tumour size and uptake of glucose derivative $\left[{ }^{18} \mathrm{~F}\right] \mathrm{FDG}$, while PDGFR $\beta$ inhibition by imatinib paradoxically increases glycolysis based on upregulation of GLUT1 protein levels. Imatinib-induced metabolic re-modelling is mediated by upregulation of hexokinase II through BRAFV600E. Blocking of PDGFR $\alpha+\beta$ results in upregulation of downstream p-ERK which triggers the increased metabolic glucose demand in BCPAP cells and tumours. Additional PDGFR $\alpha$ expression in BCPAP cells and tumours did not change glycolytic metabolism in BCPAP cells and tumours. As PDGFR $\alpha$ expression correlates with the metastatic potential in PTC, it is not a driver for glycolysis in BCPAP cells. [18${ }^{18}$ F]FDG-PET could be used to monitor the effectiveness of therapy in thyroid cancer patients and potentially treatment resistance. It remains to be proven if non-invasive determined PDGFR $\alpha$ expression in PTC patients would result in the selection of a beneficial therapy regimen using a BRAF inhibitor alone or in combination with clinically approved PDGFR $\alpha$ inhibitor to substantially decrease tumor burden for patients with metastatic disease.

\section{Declaration of interest}

Todd McMullen holds a patent entitled 'Methods, kits, and systems for treatment of metastatic papillary thyroid cancer' (US9897607B2, Feb 20,2018 ) and is an applicant for the patent 'Targeted therapy to restore radioactive iodine transport in thyroid cancer' (WO2015166355A3). The other authors have nothing to disclose.

\section{Funding}

This work was supported by the Canadian Institute of Health Research (CIHR).

\section{Acknowledgements}

The authors thank Angela Westover, Kristan Nagy-Colombo and Jeff McPherson for the production of GMP quality [ $\left.{ }^{18} \mathrm{~F}\right] \mathrm{FDG}$ and Ali Akbari for the generous production of $\left[{ }^{18} \mathrm{~F}\right] \mathrm{FLT}$. The authors thank Dan McGinn (Vivarium of the Cross Cancer Institute, Edmonton, AB, Canada) for supporting the animal work. Michael Wagner is grateful for a Canadian Institute of Health Research (CIHR) postdoctoral fellowship. The authors also gratefully acknowledge the Dianne and Irving Kipnes Foundation for supporting this work.

\section{References}

Barrio M, Czernin J, Yeh MW, Palma Diaz MF, Gupta P, AllenAuerbach M, Schiepers C \& Herrmann K 2016 The incidence of thyroid cancer in focal hypermetabolic thyroid lesions: an 18F-FDG PET/CT study in more than 6000 patients. Nuclear Medicine Communications 37 1290-1296. (https://doi.org/10.1097/ MNM.0000000000000592)

Ben-David H, Aruna BV, Seger R, Sela M \& Mozes E 2006 A 50-kDa ERKlike protein is up-regulated by a dual altered peptide ligand that suppresses myasthenia gravis-associated responses. PNAS 103 18232-18237. (https://doi.org/10.1073/pnas.0608896103)

Ciavardelli D, Bellomo M, Consalvo A, Crescimanno C \& Vella V 2017 Metabolic alterations of thyroid cancer as potential therapeutic targets. BioMed Research International 2017 2545031. (https://doi. org/10.1155/2017/2545031)

Coelho RG, Cazarin JM, Cavalcanti de Albuquerque JP, de Andrade BM \& Carvalho DP 2016 Differential glycolytic profile and Warburg effect in papillary thyroid carcinoma cell lines. Oncology Reports 36 3673-3681. (https://doi.org/10.3892/or.2016.5142)

Durante C, Haddy N, Baudin E, Leboulleux S, Hartl D, Travagli JP Caillou B, Ricard M, Lumbroso JD, De Vathaire F, et al. 2006 
Long-term outcome of 444 patients with distant metastases from papillary and follicular thyroid carcinoma: benefits and limits of radioiodine therapy. Journal of Clinical Endocrinology and Metabolism 91 2892-2899. (https://doi.org/10.1210/jc.2005-2838)

Ekpe-Adewuyi E, Lopez-Campistrous A, Tang X, Brindley DN \& McMullen TP 2016 Platelet derived growth factor receptor alpha mediates nodal metastases in papillary thyroid cancer by driving the epithelial-mesenchymal transition. Oncotarget 7 83684-83700. (https://doi.org/10.18632/oncotarget.13299)

Farwell MD, Pryma DA \& Mankoff DA 2014 PET/CT imaging in cancer: current applications and future directions. Cancer $1203433-3445$. (https://doi.org/10.1002/cncr.28860)

Faustino-Rocha A, Oliveira PA, Pinho-Oliveira J, Teixeira-Guedes C, Soares-Maia R, da Costa RG, Colaço B, Pires MJ, Colaço J, Ferreira R, et al. 2013 Estimation of rat tumor volume using caliper and ultrasonography measurements. Lab Animal 42 217-224. (https:// doi.org/10.1038/laban.254)

Feng C, Gao Y, Wang C, Yu X, Zhang W, Guan H, Shan Z \& Teng W 2013 Aberrant overexpression of pyruvate kinase M2 is associated with aggressive tumor features and the BRAF mutation in papillary thyroid cancer. Journal of Clinical Endocrinology and Metabolism 98 E1524-E1533. (https://doi.org/10.1210/jc.2012-4258)

Ferretta A, Maida I, Guida S, Azzariti A, Porcelli L, Tommasi S, Zanna P, Cocco T, Guida M \& Guida G 2016 New insight into the role of metabolic reprogramming in melanoma cells harboring BRAF mutations. Biochimica et Biophysica Acta 1863 2710-2718. (https:// doi.org/10.1016/j.bbamcr.2016.08.007)

Hamacher K, Coenen HH \& Stocklin G 1986 Efficient stereospecific synthesis of no-carrier-added 2-[18F]-fluoro-2-deoxy-Dglucose using aminopolyether supported nucleophilic substitution. Journal of Nuclear Medicine 27 235-238.

Haugen BR, Alexander EK, Bible KC, Doherty GM, Mandel SJ, Nikiforov YE, Pacini F, Randolph GW, Sawka AM, Schlumberger M, et al. 20162015 American Thyroid Association management guidelines for adult patients with thyroid nodules and differentiated thyroid cancer: the American Thyroid Association guidelines task force on thyroid nodules and differentiated thyroid cancer. Thyroid 26 1-133. (https://doi.org/10.1089/thy.2015.0020)

Hutton JE, Wang X, Zimmerman LJ, Slebos RJ, Trenary IA, Young JD, Li M \& Liebler DC 2016 Oncogenic KRAS and BRAF drive metabolic reprogramming in colorectal cancer. Molecular and Cellular Proteomics 15 2924-2938. (https://doi.org/10.1074/mcp.M116.058925)

Jans HS, Yang XH, Brooks DR, Kumar P, Wuest M \& Wiebe LI 2018 Positron emission tomography (PET) and pharmacokinetics: classical blood sampling versus image-derived analysis of [18F]FAZA and [18F] FDG in a murine tumor bearing model. Journal of Pharmacy and Pharmaceutical Sciences 21 32s-47s. (https://doi.org/10.18433/ jpps29788)

Klein Hesselink EN, Steenvoorden D, Kapiteijn E, Corssmit EP, van der Horst-Schrivers AN, Lefrandt JD, Links TP \& Dekkers OM 2015 Therapy of endocrine disease: response and toxicity of smallmolecule tyrosine kinase inhibitors in patients with thyroid carcinoma: a systematic review and meta-analysis. European Journal of Endocrinology 172 R215-R225. (https://doi.org/10.1530/EJE-14-0788)

Kraeber-Bodéré F, Carlier T, Naegelen VM, Shochat E, Lumbroso J, Trampal C, Nagarajah J, Chua S, Hugonnet F, Stokkel M, et al. 2012 Differences in the biologic activity of 2 novel MEK inhibitors revealed by 18F-FDG PET: analysis of imaging data from 2 phase I trials. Journal of Nuclear Medicine 53 1836-1846. (https://doi. org/10.2967/jnumed.112.109421)

Lee SH, Han S, Lee HS, Chae SY, Lee JJ, Song DE \& Ryu JS 2016 Association between 18F-FDG avidity and the BRAF mutation in papillary thyroid carcinoma. Nuclear Medicine and Molecular Imaging 50 38-45. (https://doi.org/10.1007/s13139-015-0367-8)

Liu JW, Chen C, Loh EW, Chu CC, Wang MY, Ouyang HJ, Chang YT, Zhuang WZ, Chou CW, Huang DJ, et al. 2018 Tyrosine kinase inhibitors for advanced or metastatic thyroid cancer: a meta-analysis of randomized controlled trials. Current Medical Research and Opinion 34 795-803. (https://doi.org/10.1080/03007995.2017.1368466)

Lopez-Campistrous A, Adewuyi EE, Benesch MGK, Ko YM, Lai R, Thiesen A, Dewald J, Wang P, Chu K, Ghosh S, et al. 2016 PDGFRo regulates follicular cell differentiation driving treatment resistance and disease recurrence in papillary thyroid cancer. EBioMedicine $\mathbf{1 2}$ 86-97. (https://doi.org/10.1016/j.ebiom.2016.09.007)

Ma J, Wu X, Li J, Wang Z \& Wang Y 2017 Prognostic value of early response assessment using (18F) FDG-PET in patients with advanced non-small cell lung cancer treated with tyrosine-kinase inhibitors. Journal of Investigative Medicine 65 935-941.

Marcus C, Whitworth PW, Surasi DS, Pai SI \& Subramaniam RM 2014 $\mathrm{PET} / \mathrm{CT}$ in the management of thyroid cancers. American Journal of Roentgenology 202 1316-1329. (https://doi.org/10.2214/AJR.13.11673)

Matrone A, Valerio L, Pieruzzi L, Giani C, Cappagli V, Lorusso L, Agate L, Puleo L, Viola D, Bottici V, et al. 2017 Protein kinase inhibitors for the treatment of advanced and progressive radiorefractory thyroid tumors: from the clinical trials to the real life. Best Practice and Research: Clinical Endocrinology and Metabolism 31 319-334. (https://doi.org/10.1016/j.beem.2017.06.001)

Nagarajah J, Ho AL, Tuttle RM, Weber WA \& Grewal RK 2015 Correlation of BRAFV600E mutation and glucose metabolism in thyroid cancer patients: an ${ }^{18}$ F-FDG PET study. Journal of Nuclear Medicine 56 662-667. (https://doi.org/10.2967/jnumed.114.150607)

Parmenter TJ, Kleinschmidt M, Kinross KM, Bond ST, Li J, Kaadige MR, Rao A, Sheppard KE, Hugo W, Pupo GM, et al. 2014 Response of BRAF-mutant melanoma to BRAF inhibition is mediated by a network of transcriptional regulators of glycolysis. Cancer Discovery 4 423-433. (https://doi.org/10.1158/2159-8290.CD-13-0440)

Pascal P, Dercle L, Weyts K, Meyer N \& Courbon F 2018 Complete metabolic response of advanced melanoma to vemurafenib assessed with FDG-PET-CT at 85 hours. Clinical Nuclear Medicine 43 333-334. (https://doi.org/10.1097/RLU.0000000000002032)

Poliaková M, Aebersold DM, Zimmer Y \& Medová M 2018 The relevance of tyrosine kinase inhibitors for global metabolic pathways in cancer. Molecular Cancer 17 27. (https://doi.org/10.1186/s12943-018-0798-9)

Prenen H, Deroose C, Vermaelen P, Sciot R, Debiec-Rychter M, Stroobants S, Mortelmans L, Schöffski P \& Van Oosterom A 2006 Establishment of a mouse gastrointestinal stromal tumour model and evaluation of response to imatinib by small animal positron emission tomography. Anticancer Research 26 1247-1252.

Ran C, Liu H, Hitoshi Y \& Israel MA 2013 Proliferation-independent control of tumor glycolysis by PDGFR-mediated AKT activation. Cancer Research 73 1831-1843. (https://doi.org/10.1158/0008-5472. CAN-12-2460)

Revheim ME, Røe K, Bruland ØS, Bach-Gansmo T, Skretting A \& Seierstad T 2011 Monitoring the effect of targeted therapies in a gastrointestinal stromal tumor xenograft using a clinical PET/CT. Molecular Imaging and Biology 13 1234-1240. (https://doi. org/10.1007/s11307-010-0464-0)

Sabbatino F, Wang Y, Wang X, Flaherty KT, Yu L, Pepin D, Scognamiglio G, Pepe S, Kirkwood JM, Cooper ZA, et al. 2014 PDGFR $\alpha$ up-regulation mediated by Sonic Hedgehog pathway activation leads to BRAF inhibitor resistance in melanoma cells with BRAF mutation. Oncotarget 5 1926-1941. (https://doi.org/10.18632/ oncotarget.1878)

Santhanam P, Khthir R, Solnes LB \& Ladenson PW 2018 The relationship of BRAFV600E mutation status to FDG PET/CT avidity in thyroid cancer: a review and meta-analysis. Endocrine Practice $\mathbf{2 4}$ 21-26. (https://doi.org/10.4158/EP-2017-0080)

Sheikhbahaei S, Mena E, Yanamadala A, Reddy S, Solnes LB, Wachsmann J \& Subramaniam RM 2017 The value of FDG PET/CT in treatment response assessment, follow-up, and surveillance of lung cancer. American Journal of Roentgenology 208 420-433. (https:// doi.org/10.2214/AJR.16.16532) https://erc.bioscientifica.com https://doi.org/10.1530/ERC-20-0135 (c) 2020 Society for Endocrinology Published by Bioscientifica Ltd. Printed in Great Britain 
Takeuchi S, Shiga T, Hirata K, Taguchi J, Magota K, Ariga S, Gouda T, Ohhara Y, Homma R, Shimizu Y, et al. 2018 Early prediction of lenvatinib treatment efficacy by using 18F-FDG PET/CT in patients with unresectable or advanced thyroid carcinoma that is refractory to radioiodine treatment: a protocol for a non-randomized singlearm multicenter observational study. BMJ Open 8 e021001. (https:// doi.org/10.1136/bmjopen-2017-021001)

Thézé B, Bernards N, Beynel A, Bouet S, Kuhnast B, Buvat I, Tavitian B \& Boisgard R 2015 Monitoring therapeutic efficacy of sunitinib using [(18)F]FDG and [(18)F]FMISO PET in an immunocompetent model of luminal B (HER2-positive)-type mammary carcinoma. BMC Cancer 15 534. (https://doi.org/10.1186/s12885-015-1540-2)

Treglia G, Mirk P, Stefanelli A, Rufini V, Giordano A \& Bonomo L 2012 18F-Fluorodeoxyglucose positron emission tomography in evaluating treatment response to imatinib or other drugs in gastrointestinal stromal tumors: a systematic review. Clinical Imaging 36 167-175. (https://doi.org/10.1016/j.clinimag.2011.08.012)

Tseng JC, Narayanan N, Ho G, Groves K, Delaney J, Bao B, Zhang J, Morin J, Kossodo S, Rajopadhye M, et al. 2017 Fluorescence imaging of bombesin and transferrin receptor expression is comparable to 18F-FDG PET in early detection of sorafenib-induced changes in tumor metabolism. PLoS ONE 12 e0182689. (https://doi.org/10.1371/ journal.pone.0182689)

Ueno D, Yao M, Tateishi U, Minamimoto R, Makiyama K, Hayashi N, Sano F, Murakami T, Kishida T, Miura T, et al. 2012 Early assessment by FDG-PET/CT of patients with advanced renal cell carcinoma treated with tyrosine kinase inhibitors is predictive of disease course. BMC Cancer 12 162. (https://doi.org/10.1186/1471-2407-12-162)

Valerio L, Pieruzzi L, Giani C, Agate L, Bottici V, Lorusso L, Cappagli V, Puleo L, Matrone A, Viola D, et al. 2017 Targeted therapy in thyroid cancer: state of the art. Clinical Oncology 29 316-324. (https://doi. org/10.1016/j.clon.2017.02.009)

Van den Abbeele AD, Gatsonis C, de Vries DJ, Melenevsky Y, SzotBarnes A, Yap JT, Godwin AK, Rink L, Huang M, Blevins M, et al. 2012 ACRIN 6665/RTOG 0132 phase II trial of neoadjuvant imatinib mesylate for operable malignant gastrointestinal stromal tumor: monitoring with 18F-FDG PET and correlation with genotype and GLUT4 expression. Journal of Nuclear Medicine 53 567-574. (https:// doi.org/10.2967/jnumed.111.094425)

Van Den Hoff J 2005 Principles of quantitative positron emission tomography. Amino Acids 29 341-353. (https://doi.org/10.1007/ s00726-005-0215-8)
Varghese F, Bukhari AB, Malhotra R \& De A 2014 IHC profiler: an open source plugin for the quantitative evaluation and automated scoring of immunohistochemistry images of human tissue samples. PLoS ONE 9 e96801. (https://doi.org/10.1371/journal.pone.0096801)

Vercellino L, Bousquet G, Baillet G, Barré E, Mathieu O, Just PA, Desgrandchamps F, Misset JL, Hindié E \& Moretti JL 2009 18F-FDG PET/CT imaging for an early assessment of response to sunitinib in metastatic renal carcinoma: preliminary study. Cancer Biotherapy and Radiopharmaceuticals 24 137-144. (https://doi.org/10.1089/ cbr.2008.0527)

Viola D, Valerio L, Molinaro E, Agate L, Bottici V, Biagini A, Lorusso L, Cappagli V, Pieruzzi L, Giani C, et al. 2016 Treatment of advanced thyroid cancer with targeted therapies: ten years of experience. Endocrine-Related Cancer 23 R185-R205. (https://doi.org/10.1530/ ERC-15-0555)

Vitiello GA, Medina BD, Zeng S, Bowler TG, Zhang JQ, Loo JK, Param NJ, Liu M, Moral AJ, Zhao JN, et al. 2018 Mitochondrial inhibition augments the efficacy of imatinib by resetting the metabolic phenotype of gastrointestinal stromal tumor. Clinical Cancer Research 24 972-984. (https://doi.org/10.1158/1078-0432. CCR-17-2697)

Wagner M, Wuest M, Hamann I, Lopez-Campistrous A, McMullen TPW \& Wuest F 2018 Molecular imaging of platelet-derived growth factor receptor-alpha (PDGFR $\alpha$ ) in papillary thyroid cancer using immunoPET. Nuclear Medicine and Biology 58 51-58. (https://doi. org/10.1016/j.nucmedbio.2017.12.005)

Wong ANM, McArthur GA, Hofman MS \& Hicks RJ 2017 The advantages and challenges of using FDG PET/CT for response assessment in melanoma in the era of targeted agents and immunotherapy. European Journal of Nuclear Medicine and Molecular Imaging 44 67-77. (https://doi.org/10.1007/s00259-017-3691-7)

Yang JH, Maciel RMB, Nakabashi CCD, Janovsky CCPS, Padovani RP, Macellaro D, Camacho CP, Osawa A, Wagner J \& Biscolla RPM 2017 Clinical utility of 18F-FDG PET/CT in the follow-up of a large cohort of patients with high-risk differentiated thyroid carcinoma. Archives of Endocrinology and Metabolism 61 416-425. (https://doi. org/10.1590/2359-3997000000285)

Yoon M, Jung SJ, Kim TH, Ha TK, Urm SH, Park JS, Lee SM \& Bae SK 2016 Relationships between transporter expression and the status of BRAF V600E mutation and F-18 FDG uptake in papillary thyroid carcinomas. Endocrine Research 41 64-69. (https://doi.org/10.3109/07 435800.2015.1066803)

Received in final form 18 June 2020

Accepted 25 June 2020

Accepted Manuscript published online 25 June 2020 (c) 2020 Society for Endocrinology Published by Bioscientifica Ltd. Printed in Great Britain 